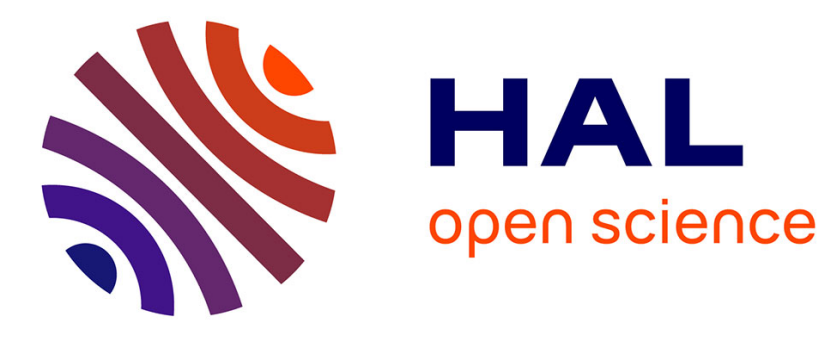

\title{
Desorption-induced shear failure of coal bed seams during gas depletion
}

D.N. Espinoza, Jean-Michel Pereira, Matthieu Vandamme, Patrick Dangla, S. Vidal-Gilbert

\section{- To cite this version:}

D.N. Espinoza, Jean-Michel Pereira, Matthieu Vandamme, Patrick Dangla, S. Vidal-Gilbert. Desorption-induced shear failure of coal bed seams during gas depletion. International Journal of Coal Geology, 2015, 137, pp.142-151. 10.1016/j.coal.2014.10.016 . hal-01118564

\author{
HAL Id: hal-01118564 \\ https://hal.science/hal-01118564
}

Submitted on 10 May 2019

HAL is a multi-disciplinary open access archive for the deposit and dissemination of scientific research documents, whether they are published or not. The documents may come from teaching and research institutions in France or abroad, or from public or private research centers.
L'archive ouverte pluridisciplinaire HAL, est destinée au dépôt et à la diffusion de documents scientifiques de niveau recherche, publiés ou non, émanant des établissements d'enseignement et de recherche français ou étrangers, des laboratoires publics ou privés. 
1

2

3

\title{
Desorption-induced shear failure of coal bed seams during gas depletion
}

\author{
D. N. Espinoza ${ }^{a}$, , J. -M. Pereira ${ }^{a}$, M. Vandamme ${ }^{a}$, P. Dangla ${ }^{a}$, S. \\ Vidal-Gilbert ${ }^{\mathrm{c}}$ \\ ${ }^{a}$ Université Paris-Est, Laboratoire Navier, (UMR 8205), ENPC, CNRS, IFSTTAR \\ ${ }^{b}$ The University of Texas at Austin, Department of Petroleum and Geosystems \\ Engineering \\ ${ }^{c}$ Total S.A., Unconventional Gas Resources
}

\begin{abstract}
The recovery of natural gas from coal bed seams is usually accompanied by a significant increase of permeability induced by coal matrix shrinkage and stress relaxation upon gas desorption. This advantageous increase in permeability may be impaired sometimes by mechanical failure of the reservoir rock and ensuing production of coal fines. Near-wellbore stress concentration and reduction of lateral stresses are known to promote shear failure during depletion in oil and gas reservoir formations. Yet, conventional analyses have shown limited success in predicting coal failure, since other chemo-physical mechanisms may be responsible in enhancing the conditions towards mechanical failure in the coal bed reservoir rock. We show a set of triaxial experiments involving gas desorption from coal cores under zero-lateral strain condition (radial stress measured and controlled) and constant total vertical stress meant to simulate the stress path during production far from the wellbore. $\mathrm{CO}_{2}$ is used a surrogate fluid for $\mathrm{CH}_{4}$. The experimental data indicates that desorption can significantly help reduce lateral stress (and
\end{abstract}


increasing deviatoric stress) until shear failure occurs. The results suggest that depletion-induced shear failure is much more likely to occur in coal seams than in conventional non-sorbing reservoir rocks. The adsorptionmechanical coupling turns out to be a key phenomenon in the process. Numerical simulations at the representative elementary volume scale adopting a double-porosity poromechanical model support the experimental findings and permit calculating a critical gas pressure for shear failure to happen. This emergent phenomenon is comparable to the outcome of other situations such as mineral dissolution or thermal contraction, where shrinkage relaxes lateral stress and acts as an intensifying driver for promoting shear failure within the reservoir rock. Coupled numerical simulation is needed to include near-wellbore effects and validate our findings with actual field observations. A thorough understanding of the coupled response of coal seams is necessary to enhance reservoir management and mitigate the effects of coal failure on fines production.

Keywords: fines production, CBM, adsorption, swelling, nanoporosity, faulting, chemo-mechanical coupling

\section{Introduction}

2 Currently, natural gas accounts for roughly 20\% of the World's energy 3 supply (IEA, 2013). Coal bed methane constitutes an important domestic 4 source of natural gas in several countries, namely Australia, USA, Canada 5 and China (EIA, 2013). Moreover, production of coal bed methane is ex6 pected to increase throughout the world in the near future as more reservoirs 7 are discovered and new technology enables enhanced production. 
Various characteristics make coal beds a unique geomaterial, showing poromechanical properties notably different from other reservoir rocks. First, coal seams are naturally fractured reservoirs. Diagenetic processes lead to opening mode fractures predominantly oriented perpendicularly to the bedding plane, called cleats (Laubach et al., 1998). Cleats compose most of the macroporosity, where fluid flow occurs by advection (Mazumder et al., 2006; Pan and Connell, 2007). Second, the coal solid skeleton is constituted by a microporous disordered organic continuum, termed coal matrix. Micropores and mesopores sized in the order of $10^{-9}$ to $10^{-8} \mathrm{~m}$ compose the coal microporosity. The coal matrix is capable of adsorbing various gases, including carbon dioxide $\mathrm{CO}_{2}$, methane $\mathrm{CH}_{4}$, and nitrogen $\mathrm{N}_{2}$; adsorption leads to coal matrix volumetric swelling in the order of a few percents (Reucroft and Sethuraman, 1987; Ceglarska-Stefanska and Czaplinski, 1993; Levine, 1996; Mazumder et al., 2006; Pan and Connell, 2007; Pini, 2009). Conversely, desorption leads to coal matrix shrinkage.

Bottom-hole depressurization induces gas production from fractures and desorption from the coal matrix during the production phase. Desorptioninduced shrinkage has an important effect on coal seam permeability (Palmer and Mansoori, 1998; Pan and Connell, 2012). Shrinkage favors the opening of open-mode fractures with a concomitant increase in permeability. However, large increases in permeability during depletion have sometimes been observed to be followed by a sudden drop of permeability (Figure 1), usually accompanied by the production of coal fines (Moore et al., 2011; Okotie and Moore, 2010). One cause of fines production (also responsible for sand production in conventional reservoir) is increased stress anisotropy and shearing 


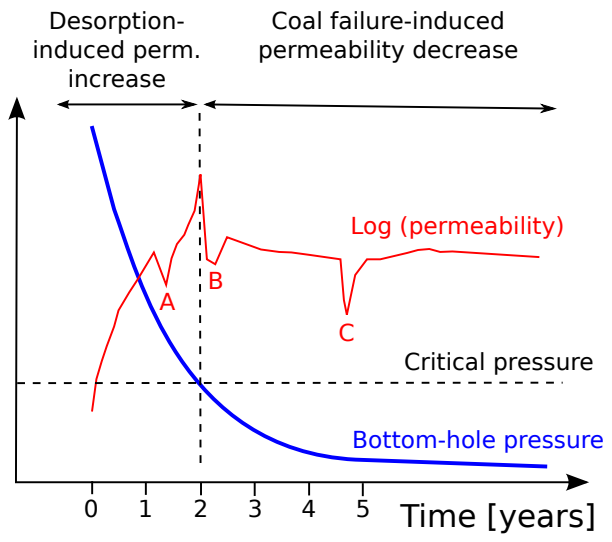

Figure 1: Schematic signature of reservoir response and coal failure during depletion as a function of time: bottom-hole pressure and permeability signals. Notice that sudden permeability reductions (indicated A, B and C) take place as bottom-hole pressure is reduced. The permeability drops are associated with coal failure events. The last permeability drop (C) is recovered after wellbore clean-up operations only. Adapted from field experimental data by Moore et al. (2011).

around uncased wells or perforations due to loss of radial support.

Reservoir depletion is known to induce changes in effective stresses in the reservoir rock far from the wellbore, that can sometimes lead to shear failure and fault reactivation within the reservoir. Depletion promotes zero-lateral strain loading condition in laterally extensive reservoirs (condition commonly known as uniaxial strain/compression in Petroleum Engineering and Structural Geology or oedometric condition in Geotechnical Engineering- Figure 2 ). The change in stresses upon depletion in conventional reservoirs is well predicted by poroelasticity, shear-failure (induced normal faulting), or a combination of both (Teufel et al., 1991; Segall and Fitzgerald, 1998; Goulty, 2003). Under zero-lateral strain condition, the ratio between the change of total lateral (horizontal) stress $\Delta \sigma_{h}$ and the change of reservoir pressure $\Delta p$ 


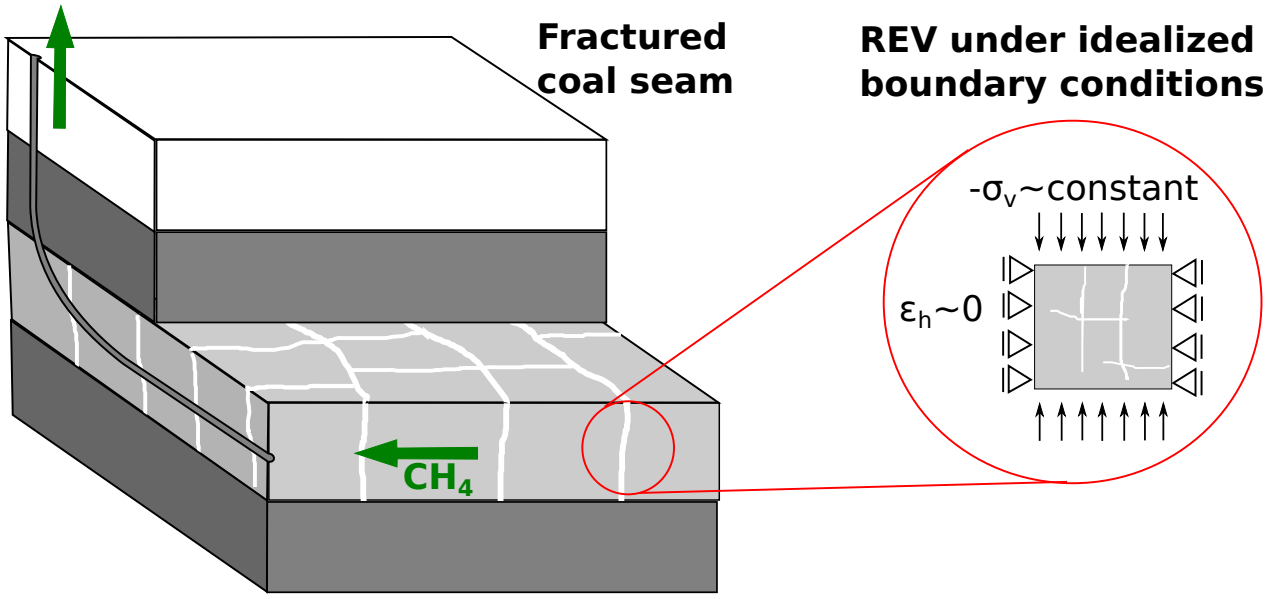

Figure 2: Schematic representation of a coal seam intercepted by a horizontal well and of a representative elementary volume (REV) far from near-wellbore effects. Laterally extensive coal seams follow zero-lateral strain compression far from the wellbore.

is equal to $\Delta \sigma_{h} / \Delta p=2 / 3$ for a poroelastic response with Poisson's ratio $\nu=0.25$ and Biot's coefficient $\alpha=1$ or for shear failure with friction coefficient $\mu=0.58$. Recent experimental work shows a reduction of $9.4 \mathrm{MPa}$ of lateral stress upon drawdown of $\mathrm{CH}_{4}$ gas pressure from 6.2 to $0.3 \mathrm{MPa}$ 
Recent work from the authors aims at predicting adsorption-induced strains and stresses in coal seams within a poromechanical framework including rigorously adsorption phenomena (Brochard et al., 2012; Nikoosokhan et al., 2012, 2014; Espinoza et al., 2013, 2014). Our experimental and modeling results indicate that adsorption can generate significant stresses in the order of tens of MPa at typical reservoir pressures. Hence, it should not be surprising that desorption at zero-lateral strain can significantly affect the reduction of lateral stress during depletion at a $\Delta \sigma_{h} / \Delta p$ rate much greater than the one due solely to poroelastic effects in macropores predicted by conventional poroelasticity.

The objective of this study is to assess the reduction of lateral stresses in coal seams during depletion and gas desorption by replicating the depletion pressure-stress path in the laboratory using $\mathrm{CO}_{2}$ as a surrogate fluid for $\mathrm{CH}_{4}$. We aim at understanding the underlying phenomena which lead to coal failure and production of coal fines at the scale of a representative elementary volume far from near-wellbore effects.

\section{Materials and Methods}

\subsection{Coal characterization and triaxial testing}

We test coal originary from South Africa (Vitrinite reflectance $0.57 \%$ - subbituminous A/high volatile C bituminous by ASTM D 388). A set of cores $38 \mathrm{~mm}$ diameter and 2:1 slenderness drilled perpendicularly to the bedding plane serve as experimental specimens. The bulk density of cores ranges from 1318 to $1356 \mathrm{~kg} / \mathrm{m}^{3}$. The specimen Helium porosity varies from 11-to$13 \%$. Core testing takes place in a triaxial cell connected to syringe pumps 
a)

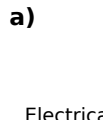

$$
\begin{aligned}
& \text { Electrical } \\
& \text { feedthroughs }
\end{aligned}
$$
Coal specimen
2:1 \& membrane
Downstream $\mathrm{CO}_{2}$ pump

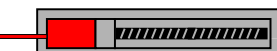

Oil pump (Axial stress)

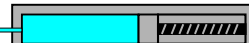

Oil pump (Radial stress)

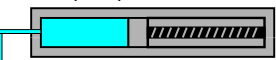

Upstream $\mathrm{CO}_{2}$ pump

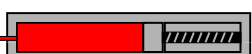

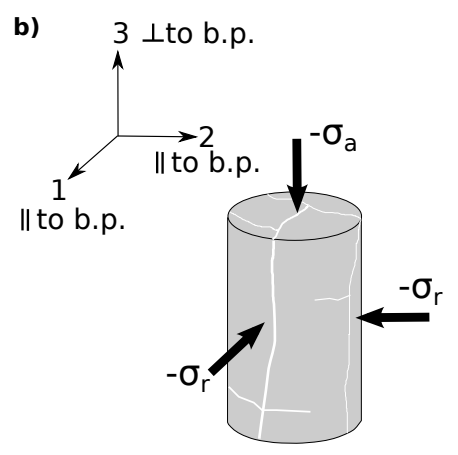

Figure 3: a) Experimental triaxial device; main characteristics include: maximum radial stress $40 \mathrm{MPa}$, maximum axial stress $60 \mathrm{MPa}$, measurement of local strains through LVDTs, temperature control and ability to handle pressurized pore-fluids. b) Orientation of the specimen respect to the bedding plane (b.p.).

to control stresses and pore-fluid pressure. The system is able to (1) measure specimen axial and radial deformations and (2) control independently axial and radial stresses to apply isotropic or anisotropic state of stresses (including zero-lateral strain condition). Figure 3 shows a schematic representation of the triaxial cell and its main features.

\subsection{Determination of shear strength}

We tested the shear strength of coal cores in dry conditions (without adsorbed gas) under unconfined and confined triaxial conditions. The triaxial cell imposes a deviatoric loading by applying a change in axial strain with time at a given constant confinement. The axial strain rate is fixed to a constant value equal to $3 \cdot 10^{-4} \mathrm{~min}^{-1}$. Rigorously, the shear strength should be tested with sorbed gas, as sorption may reduce shear strength (See section 4.1 Fluid-specific effects). 


\subsection{Desorption test procedure}

We aim at simulating in the laboratory the pressure-stress path of a block of coal subjected to depressurization and depletion. Hence, the following pressure-stress path is required: (1) recreation of in-situ initial state of stresses and seam pressure (requires adsorbed gas in thermodynamical equilibrium with gas in the cleats), (2) imposition of a pressure drawdown to extract gas from the fractures and coal micropores, with simultaneous adjustment of lateral stresses to keep zero-lateral strain condition, while the total vertical stress remains constant (constant overburden - see Figure 2).

The experimental procedure to achieve the pressure-stress path described above consists of the following steps:

1. Increase confining stresses 1 to $2 \mathrm{MPa}$ above the objective fluid injection pressure $p_{c i}$ at which the core will be exposed. The resulting low effective stress will facilitate quick advective gas flow through fractures (since fracture permeability is highly sensitive to effective stress) and reduce equilibration time in the next step.

2. Inject $\mathrm{CO}_{2}$ at constant confining stress, let the specimen swell and equilibrate for $\sim 7$ days. Swelling strains help us evaluate thermodynamical equilibrium, such that when they reach steady-state values we consider equilibrium has been attained.

3. Increase effective stresses to the initial stress conditions representing the current in-situ stresses in the formation. Let the specimen equilibrate again for at least 1 day.

4. Apply a drawdown pressure by imposing constant pressures at the two loading caps $p_{D S}<p_{U S}<p_{c i}\left(p_{D S}\right.$ : pressure downstream, $p_{U S}$ : pres- 
sure upstream).

5. The pressure drawdown induces axial and radial deformations. The radial deformation is canceled periodically (to keep variations smaller than $\Delta \varepsilon_{r}<3 \cdot 10^{-4}$ ) by reducing the total radial stress in order to maintain near zero-lateral strain condition. No action is taken on the axial direction, so that total axial stress remains constant.

All tests are performed under stress, pressure, and temperature relevant to in-situ coal bed conditions. Instead of $\mathrm{CH}_{4}$, we utilize $\mathrm{CO}_{2}$ as the pore fluid. The applicability of our $\mathrm{CO}_{2}$ laboratory results to $\mathrm{CH}_{4}$ desorption are discussed in Section 4.1.

\section{Experimental results}

\subsection{Dry testing - Shear failure envelope}

Table 1 lists all shear strength experiments. Figure 4 shows an example of a coal core failed under simple compression. Specimens V4, V5, and V6 were tested under unconfined conditions while specimens V7 and V9 were tested under confined triaxial conditions. Figure 5 shows the summary of shear strength results with Mohr circles at failure. The shear strength increased non-linearly with added confining stress. The friction angle estimated from the orientation of shear fractures in failed specimens is $\phi \sim 40^{\circ}$ to $50^{\circ}$. The best-fitting parameters for the Hoek-Brown criterion $\sigma_{1}^{\prime}=\sigma_{3}^{\prime}+\sigma_{U C S}^{\prime} \sqrt{m \sigma_{3}^{\prime} / \sigma_{U C S}^{\prime}+s}$ in terms of Terzaghi's effective stress defined as $\sigma^{\prime}=-\left(\sigma+p_{c}\right)$ are $s=1, \sigma_{U C S}^{\prime}=22.05 \mathrm{MPa}$ and $m=38.4$. Pressure $p_{c}$ is zero an all experiments listed in Table 1. 
Table 1: List of shear strength experiments on dry specimens. $\left({ }^{*}\right)$ Acquisition error stress signal lost.

\begin{tabular}{c|c|c}
\hline \hline Specimen & $\begin{array}{c}\text { Terzaghi's effective } \\
\text { radial stress } \\
\sigma_{r}^{\prime}[\mathrm{MPa}]\end{array}$ & $\begin{array}{c}\text { Terzaghi's effective } \\
\text { axial stress } \\
\sigma_{a}^{\prime}[\mathrm{MPa}]\end{array}$ \\
\hline V4 & 0.0 & $>17^{*}$ \\
\hline V5 & 0.0 & 20.7 \\
\hline V6 & 0.0 & 22.2 \\
\hline V7 & 3.0 & 55.0 \\
\hline V9 & 1.5 & 48.0 \\
\hline \hline
\end{tabular}

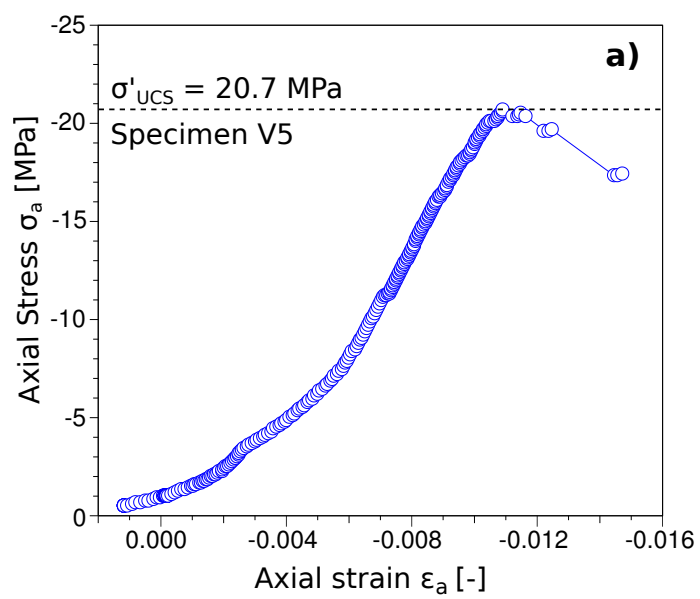

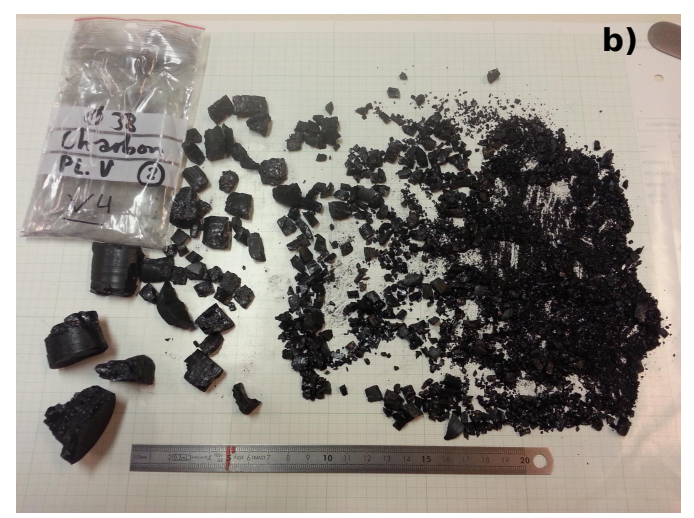

Coal failed under simple compression

Figure 4: Unconfined compression test: a) stress-strain curve, and b) picture of sheared coal as extruded out from the testing sleeve; fragments are ordered from left to right according to their size. 


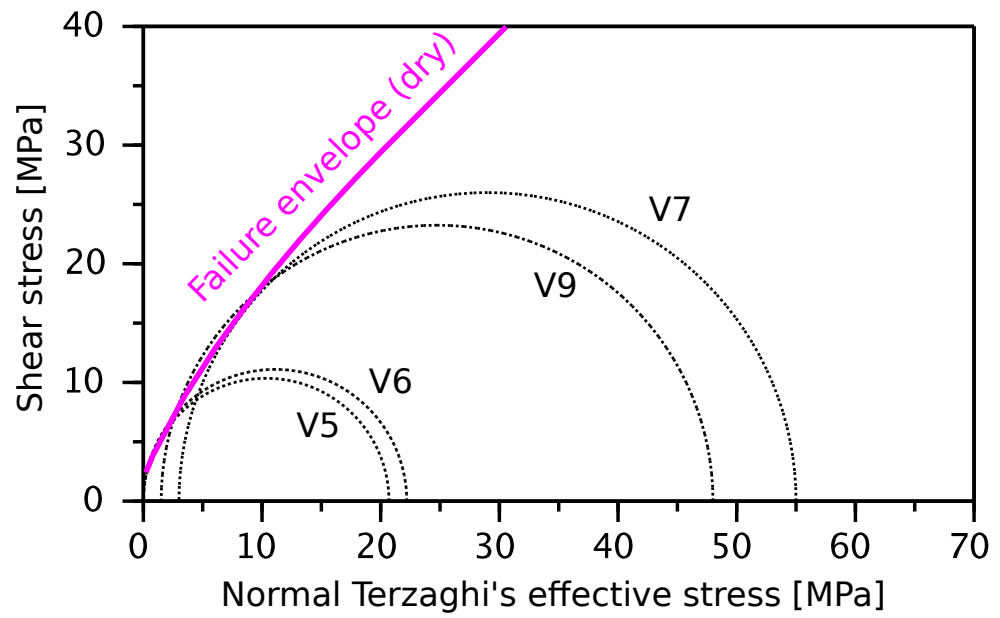

Figure 5: Summary of triaxial shear tests with Mohr circles at failure. The pink line represents the Hoek-Brown fitted shear failure envelope of dry specimens.

\section{2. $\mathrm{CO}_{2}$ testing - Desorption-induced shear failure}

Table 2 lists the initial (subindex $i$ ) and final conditions (subindex $f$ ) of all desorption experiments performed. The experiments are carried out at $39 \pm 1^{\circ} \mathrm{C}$. Seven days of exposing the coal core to $\mathrm{CO}_{2}$ are quite likely enough to allow significant sorption, because in this time frame the measured swelling strains reached steady state values in the order of 2 to $3 \%$ attributable only to adsorption. Figure 6 shows the experimental time history of specimen V2b upon desorption. Depressurization starts at 0.112 days, moment at which the pressure of the loading cap downstream is regulated to $p_{D S}=1 \mathrm{MPa}$. Five minutes later, the pressure at the loading cap upstream is regulated to $p_{U S}=1.5 \mathrm{MPa}$. Notice that at this time the fluid pressure in the cleats is likely to be higher than the pressure regulated at loading caps. 15 minutes after having regulated the pressure at the loading cap upstream, the pressure at the loading cap downstream is regulated one more time to $p_{D S}=0.5 \mathrm{MPa}$. 
Table 2: List of $\mathrm{CO}_{2}$ zero-lateral strain desorption experiments: initial and final pressurestress conditions.

\begin{tabular}{c|ccc|ccc}
\hline \hline Specimen & \multicolumn{3}{|c|}{ Initial conditions } & \multicolumn{3}{c}{ Final conditions } \\
& $\begin{array}{c}p_{c i} \\
{[\mathrm{MPa}]}\end{array}$ & $\begin{array}{c}\sigma_{r i} \\
{[\mathrm{MPa}]}\end{array}$ & $\begin{array}{c}\sigma_{a i} \\
{[\mathrm{MPa}]}\end{array}$ & $\begin{array}{c}p_{c f} \\
{[\mathrm{MPa}]}\end{array}$ & $\begin{array}{c}\sigma_{r f} \\
{[\mathrm{MPa}]}\end{array}$ & $\begin{array}{c}\text { Failure } \\
{[\mathrm{Y} / \mathrm{N}]}\end{array}$ \\
\hline $\mathrm{V} 2 \mathrm{a}$ & 10.0 & -21.0 & -22.0 & 1.0 & -2.0 & $\mathrm{~N}$ \\
\hline $\mathrm{V} 3 \mathrm{a}$ & 5.0 & -6.0 & -10.0 & 0.5 & -0.6 & $\mathrm{~N}$ \\
\hline $\mathrm{V} 2 \mathrm{~b}$ & 10.0 & -15.0 & -30.0 & $1.5-0.5$ & -2.0 & $\mathrm{Y}$ \\
\hline $\mathrm{V} 3 \mathrm{~b}$ & 10.0 & -15.0 & -30.0 & 1.0 & -3.0 & $\mathrm{Y}$ \\
\hline \hline
\end{tabular}

This experiment shows that the result of depressurization and desorption at zero-lateral strain is a reduction of $13 \mathrm{MPa}$ of radial stress. Failure (at constant total vertical stress) manifests itself through the measured variables as a rapid homogenization of the pressures upstream and downstream (shear fractures form) and a rapid change of strains in axial (contraction) and radial (expansion) directions. The radial strain is not controllable anymore after the onset of failure.

Figure 7 shows the experimental data from Figure 6 plotted independently of time. Figure 7 -a shows the change of strain as a function of total radial stress. Radial strain $\varepsilon_{r}$ remains nearly constant till the onset of failure. Figure 7-b shows the change of total stresses as a function of the mean $\mathrm{CO}_{2}$ pressure upstream and downstream. Figure 7-c shows the effective stress path of the apex of the Mohr circle. Recall that $p_{c}$ is not homogeneous through the specimen and its average value is unknown shortly after depressurization. Terzaghi's effective stress is computed with an average value of $\mathrm{CO}_{2}$ pressure: $\sigma_{r}^{\prime}=-\left[\sigma_{r}+\left(p_{U S}+p_{D S}\right) / 2\right]$ and $\sigma_{a}^{\prime}=-\left[\sigma_{a}+\left(p_{U S}+p_{D S}\right) / 2\right]$. The increase 

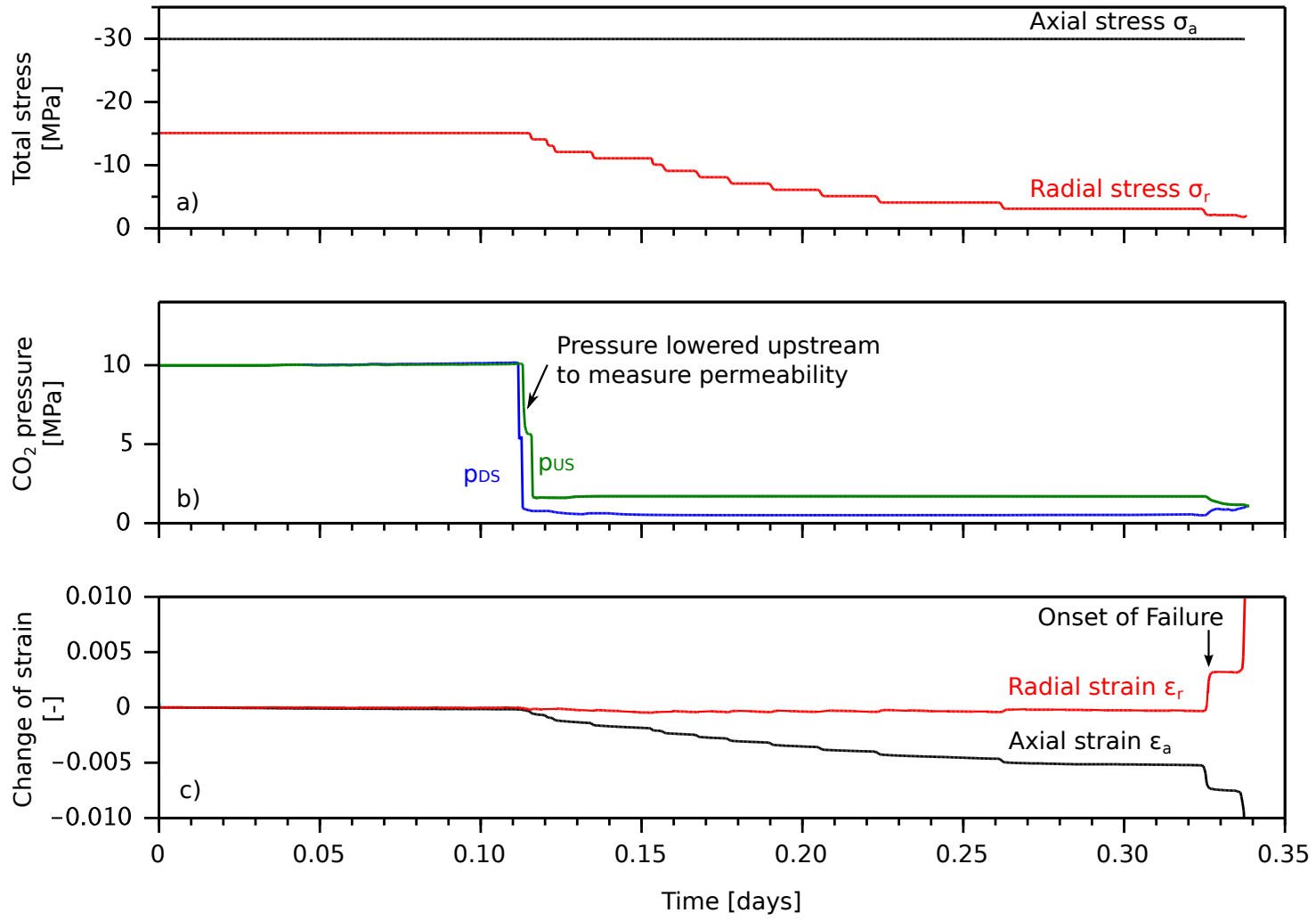

Figure 6: Time history of experiment V2b: a) total stresses, b) fluid pressure measured at upstream and downstream loading caps (a pressure gradient is applied to measure permeability), and c) change of strain respect to equilibrium initial conditions. 

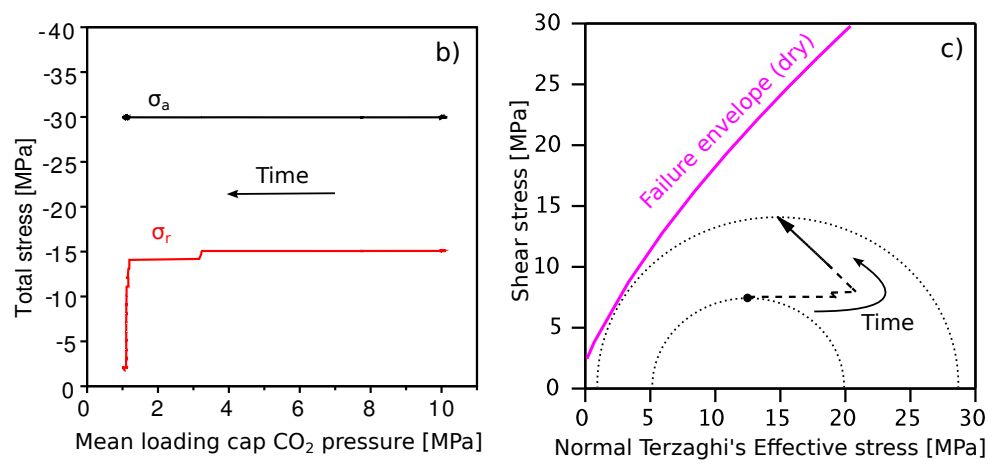

Figure 7: Experimental data from experiment V2b: a) deformation as a function of radial stress, b) path of total stresses as a function of the mean $\mathrm{CO}_{2}$ pressure upstream and downstream $\left(p_{U S}+p_{D S}\right) / 2$, and c) path of the apex of the Terzaghi's effective stress Mohr circle (the pressure in the cleats $p_{c}$ is not well approximated by the average loading cap pressures right after depressurization - plotted as dashed lines).

174 in deviatoric stress is clearly manifested by an increase in the radius of the

Mohr circle. Specimen V2b fails upon desorption at a state of stress which nearly touches the failure envelope fitted for coal cores from the same seam without $\mathrm{CO}_{2}$.

Figure 8 shows post-testing X-ray computed tomography images of specimen V2b. The images confirm pervasive shear failure all over the specimen. Many fractures seem to be initiated at pre-existing fractures and continue through lamination layers.

Experiment V3b showed a response to desorption similar to that of specimen V2b. Shear failure occurred by gradual but steady increase in axial strain, much less abruptly than in experiment V2b. Experiments V2a and V3a experienced desorption-induced reduction of lateral stress but did not achieve shear failure. Notice that experiment V3a reaches nearly zero Terzaghi's effective radial stress. At this point, the radial confining pressure (ra- 

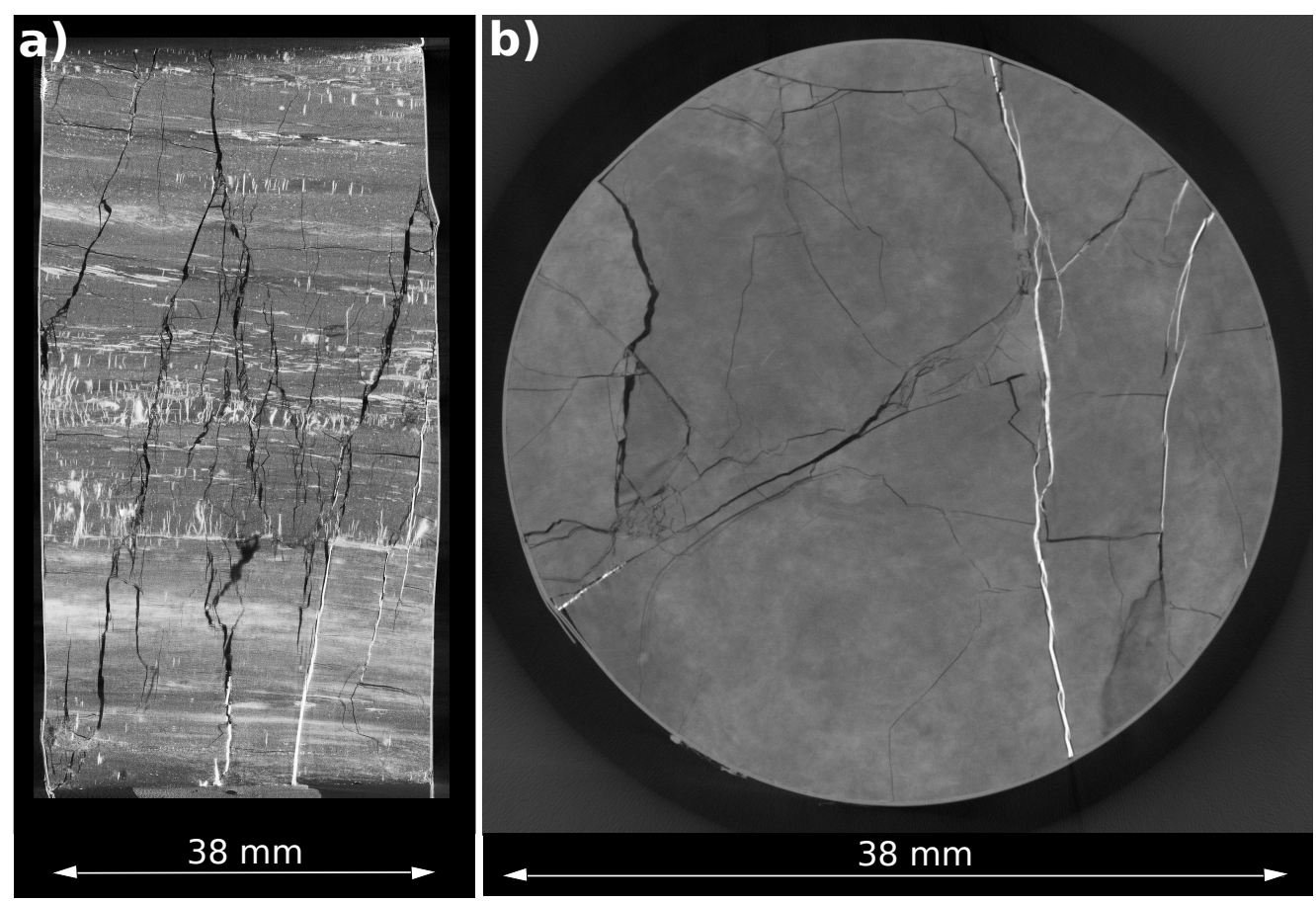

Figure 8: Coal specimen V2b after desorption-induced shear failure imaged by X-ray computed tomography at Laboratoire Navier (navier.enpc.fr/Microtomographe): a) vertical cross section and b) horizontal cross section. Intense white regions represent calcite-filled fractures. Diffuse white regions indicate higher clay-content lamination layers. Dark black stands for voids and empty fractures. Resolution: $25 \mu \mathrm{m}$. Note: the specimen is still contained by confining membrane at the time of X-ray imaging. 
dial stress) cannot be reduced to compensate shrinkage because otherwise the pore-fluid would escape into the confining fluid. Thus, zero-lateral strain condition cannot be held anymore after this point and the specimen continues to desorb shrinking in all directions. Similarly, shear failure does not indicate the end of desorption. Cores from experiments V2b and V3b likely continued to desorb and shrink after shear failure.

\section{Discussion}

\subsection{Fluid-specific effects and scale effects}

The underlying physical mechanisms and geomechanical consequences are expected to be qualitatively similar with $\mathrm{CH}_{4}$ and $\mathrm{CO}_{2}$. Nonetheless, two points must be considered to project our experimental results to CBM applications.

First, $\mathrm{CO}_{2}$ adsorption-induced strains are nearly two to three times as high as the ones induced by $\mathrm{CH}_{4}$ adsorption at the same bulk fluid pressure (Chikatamarla et al., 2009; Pini, 2009; Pan and Connell, 2011). Independent gravimetric sorption measurements on crushed coal from the same formation as the one tested here show that the maximum excess sorption of $\mathrm{CO}_{2}$ is $1.4 \mathrm{mmol} / \mathrm{g}$, about twice as high as the maximum excess sorption of $\mathrm{CH}_{4}$ (experiments performed by BGC-Analytik UG). Hence, our laboratory experimental results present a scenario considerably more likely to induce shear failure by desorption as it would be the case using $\mathrm{CH}_{4}$.

Second, various studies indicate changes in geomechanical parameters with $\mathrm{CO}_{2}$ sorption, including reduction of Young's mudulus (Masoudian et al., 2013, 2014; Hol et al., 2014), reduction of unconfined compression 
strength (Czaplinski and Holda, 1982), enhanced creep (Hagin and Zoback, 2010) and microfracturing (Hol et al., 2012) when coal is exposed to CO2 sorption. Although $\mathrm{CO}_{2}$ may affect the coal matrix in ways that $\mathrm{CH}_{4}$ may not, our results show little affect of $\mathrm{CO}_{2}$ sorption on the shear strength of coal cores with natural fractures compared to dry coal. Similarly to coal cores, the shear strength of the coal seam will be dominated by pre-existing planes of weakness.

\subsection{Failure mechanism}

Let us evaluate the state of stresses of a representative elementary volume (REV) of a coal seam through its effective stress Mohr circle. Terzaghi's effective stress (defined as $\left.\sigma^{\prime}=-\left(\sigma+p_{c}\right)\right)$ is used since in this section we at evaluating failure rather than deformation (Boutéca and Guéguen, 1999). Figure 9 shows a series of steps that illustrate the proposed failure mechanism. These steps are summarized as follows:

1. Assume the original conditions correspond to a normal faulting regime such that the absolute value of total vertical stress $\sigma_{V}$ is higher than the maximum $\sigma_{H \max }$ and minimum horizontal stresses $\sigma_{h \min }\left(\left|\sigma_{V}\right|>\right.$ $\left.\left|\sigma_{\text {Hmax }}\right|>\left|\sigma_{h \min }\right|\right)$ and that the effective stress anisotropy ratio $\sigma_{V}^{\prime} / \sigma_{h}^{\prime}$ is below the critical value for promoting shear failure (where horizontal stresses are assumed to be the same $\sigma_{h}=\sigma_{\text {Hmax }}=\sigma_{\text {hmin }}$ for the sake of simplicity).

2. Under zero-lateral strain condition, a fluid pressure reduction in the fractures increases effective stresses $\sigma_{V}^{\prime}$ and $\sigma_{h}^{\prime}$. According to linear isotropic poroelasticity, the increases in Terzaghi's effective stress are 
$\Delta \sigma_{V}^{\prime}=-\Delta p_{c}$ and $\Delta \sigma_{h}^{\prime}=\left[(1-2 \nu)(1-\nu)^{-1} \alpha-1\right] \Delta p_{c}$, with $\alpha$ the Biot coefficient, $\nu$ the Poisson's ratio, and $\Delta p_{c}<0$ the reservoir change in pressure due to depletion. Thus, the shear stress $\left(\sigma_{V}^{\prime}-\sigma_{h}^{\prime}\right) / 2$ increases by $-\alpha(1-2 \nu)[2(1-\nu)]^{-1} \Delta p_{c}$ and the average stress $\left(\sigma_{V}^{\prime}+\sigma_{h}^{\prime}\right) / 2$ increases by $\left\{\alpha(1-2 \nu)[2(1-\nu)]^{-1}-1\right\} \Delta p_{c}$ upon reservoir depletion.

3. Desorption induces coal matrix shrinkage, which, given the zero-lateral strain condition, upscales as a reduction of compressive effective lateral stress $\Delta \sigma_{h}^{\prime}$. If desorption takes place at constant gas pressure in the fractures, i.e., desorbed gas is quickly drained compared with desorption times, then the effective vertical stress remains constant, so that, only the lateral effective stress changes.

4. The lateral stress reduction induced by desorption increases stress anisotropy until a situation in which coal shear failure may occur, depending on the coal shear strength and initial pressure-stress conditions.

Our experiments (see Figure 7-c) show that the above proposed mechanism is quite likely to explain the stress path observed experimentally and the stress path that a coal seam in the field would go through upon depletion. Step 2 (poroelastic shrinkage) could not be measured in the laboratory because the $\mathrm{CO}_{2}$ pressures upstream and downstream are regulated early to facilitate rapid desorption and set with a pressure gradient of about $1 \mathrm{MPa}$. The upper bound for fracture-induced poroelastic increase in maximum shear stress is $-\alpha(1-2 \nu)[2(1-\nu)]^{-1} \Delta p_{c}$. Consider $\nu=0.3$ and $\alpha=1$, the change in shear stress of specimen V2b upon depressurization of the cleat system $\left(\Delta p_{c}=9 \mathrm{MPa}\right)$ should be at most $\sim 2.6 \mathrm{MPa}$. Figure 7 -c shows an increase of maximum shear stress of about $14 \mathrm{MPa}$, about five times higher than the 
Stress path of coal seam REV far from the near-wellbore effects

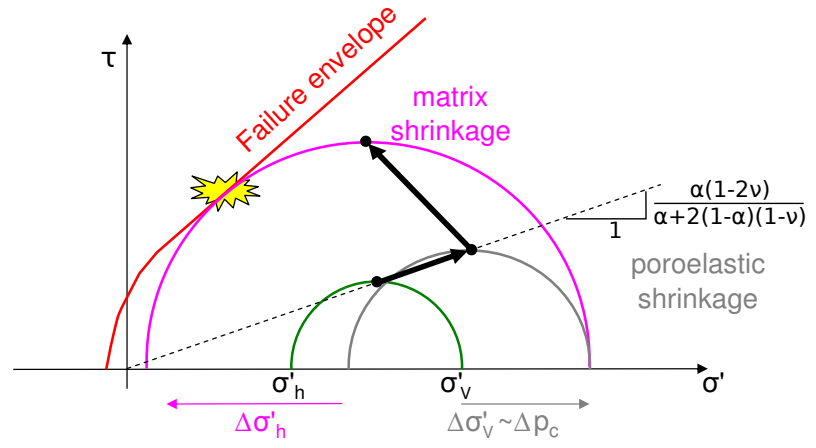

1 - Original normal faulting conditions $\sigma_{\mathrm{V}}^{\prime}>\sigma_{\mathrm{h}}^{\prime}$

2 - Rapid depressurization $\Delta \sigma^{\prime} \sim \Delta p_{c} ; \Delta \sigma_{h}^{\prime} \sim\left[\alpha(1-2 v)(1-v)^{-1}-1\right] \Delta p_{c}$

3 - Slow desorption $\Delta \sigma_{\mathrm{h}}^{\prime}<0$ at $\varepsilon_{\mathrm{h}} \sim 0$

4 - Shear failure

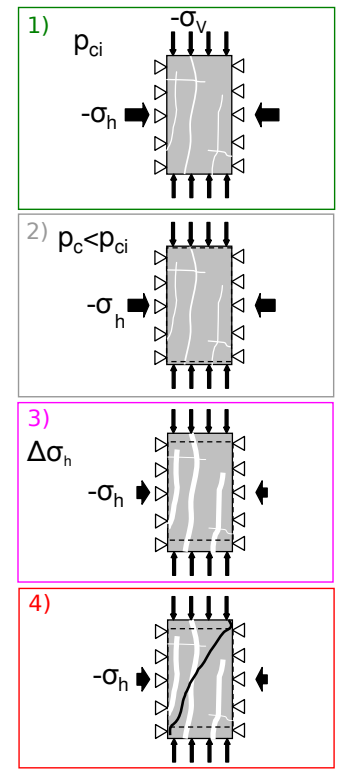

Figure 9: Mechanism for desorption-induced shear failure of coal seams in terms of effective stresses: 2-D Mohr circle representation and stress path.

value expected for poroelastic shrinkage, supporting the fact that desorption played a role decreasing the absolute value of radial stress. The absolute value of total radial stress measured in all experiments showed a clear and steady reduction at constant upstream/downstream pressure $\left(\mathrm{CO}_{2}\right.$ is drained as it desorbs - see Table 2). The resulting stress path (at constant fluid pressure) is a movement of the apex of the Mohr circle in direction up-left, which can only be explained by shrinkage of the solid skeleton, in this case driven by desorption-mechanical coupling.

\subsection{Reservoir space analysis}

The stress path of the coal reservoir can also be analyzed in terms of total stresses (see Figure 10). First, reservoir depletion under zero-lateral strain induces a poroelastic reduction of the absolute value of total lateral 
stress equal to $\Delta \sigma_{h}=A \Delta p_{c}$ where $A=-\alpha(1-2 \nu) /(1-\nu)$ (positive when compression stresses are assumed positive - Segall and Fitzgerald (1998)). Next, desorption-induced shrinkage manifests itself as a decrease of lateral stress at constant fluid pressure in fractures (assuming that desorbed gas quickly drains through the fractures). The actual path (a combination of both phenomena) would depend on the rate of transfer of fluid from the matrix to the fractures, the permeability of fractures, and the distance of the coal block to the wellbore. The likelihood to achieve failure depends on the initial stress conditions, the initial pore pressure, the amount of sorbed fluid, the drawdown pressure, and the adsorptive-mechanical properties of the coal matrix. As regards initial stress conditions, coal seams in a normal faulting environment would be more prone to shear failure by reduction of lateral stresses than in a reverse or strike-slip faulting environment. Figure 10 highlights the fact that horizontal stresses can decrease significantly more in sorbing rocks than in non-sorbing rocks subjected to depletion.

\subsection{Application to field conditions and impact of coal failure on seam per-} meability

The experimental and modeling results presented in this study are valid for zero-lateral strain condition with constant total vertical stress. Further validation is needed in areas where boundary conditions are different, such as near the wellbore, near hydraulic fractures if any, in the flanks of the reservoir, and whenever stress overarching develops in the caprock. For example, wellbore direction respect to the principal stresses would affect the state of stresses near wellbore. Casing and perforations if any would also modify the state of stresses near the wellbore. A coupled numerical solver is 


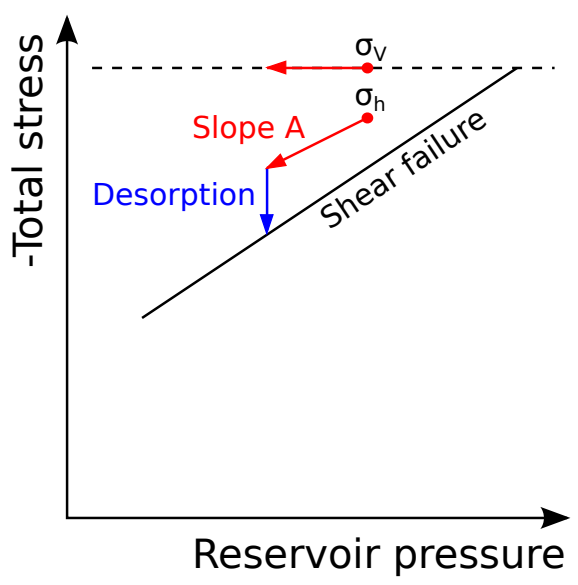

Figure 10: Reservoir space analysis of desorption-induced shear failure in coal seams subjected to depletion.

needed to analyze full scale well production and match modeling predictions to observations in the field at specific sites.

Shear failure in coal seams is not detrimental to permeability per se. For example, induced shear failure within chalk reservoirs in the North Sea is thought to be responsible for keeping high reservoir permeability in spite of significant matrix porosity reduction (Teufel et al., 1991). What is detrimental for permeability is the production of fines during shearing and the loss of hydraulic head due to fines clogging in originally clean fractures. Hence, reservoir management can be aimed at (1) managing fines by casing wellbores or screening the fines, or (2) finding the maximum drawdown pressure for which the coal seam does not fail in shear. Alternative (2) requires a poromechanical model which can capture the reduction of lateral stress induced by desorption (see Section 5).

In addition to $\mathrm{CH}_{4}$ depletion, $\mathrm{CO}_{2}$ injection may also induce coal shear failure (Palmer, 2008). In the context of the experimental evidence presented 
here, this could be explained by an excessive increase of lateral stress induced by adsorption which could lead to failure in reverse faulting stress regime within the coal seam.

\subsection{Other chemo-thermo-mechanical couplings leading to lateral stress re-} laxation and induced shear failure

Natural and anthropogenic lateral stress relaxation phenomena have been observed in various cases. First, polygonal faults form in the absence of tectonic stresses and are believed to originate from the volumetric contraction of sedimentary layers; the mechanism of contraction has been linked to water expulsion from the pore space upon overburden loading and thermal contraction (Cartwright and Lonergan, 1996). Recent findings show that mineral dissolution during rock diagenesis can contribute to a relaxation of lateral stress in sedimentary basins (Shin et al., 2010). Second, cold water injection in hot reservoirs causes thermal contraction. Thermal contraction contributes to decrease lateral stresses. Evidence from enhanced geothermal energy recovery sites shows significant induced seismicity caused by a combination of rock cooling and reduction of effective stress with ensuing shear slip of optimally oriented fractures (Majer et al., 2007). Sharp temperature gradients may even induce open mode fractures and rock spalling (Dikken and Niko, 1987).

\section{Geomechanical modeling}

Section 3 presents experimental evidence indicating that desorption under zero-lateral strain condition leads to reduction of lateral stress, increased stress anisotropy, and eventually to shear failure. Here we show a numerical 
simulation of the experiment V2b (Figures 6 and 7) using a double porosity poromechanical model with coal core and matrix parameters measured for the same coal by Espinoza et al. (2014). We add an additional numerical simulation of what would be expected for the same coal core subjected to $\mathrm{CH}_{4}$ desorption. The shear strength of "dry" coal measured in Section 3.1 is used as an upper bound of the shear strength of coal that would be expected for coal saturated with gas.

\subsection{Theoretical modeling}

We have developed a double porosity poromechanical model for transverse isotropic coal seams (Nikoosokhan et al., 2012; Espinoza et al., 2014). This model is based on the embedment of an adsorptive-mechanical model of the coal matrix (which develops adsorption stresses $s^{a}$ ) into a larger fractured poroelastic medium (the coal seam - with stiffness moduli $C_{i j}$ and Biot coefficients $\alpha_{h}$ and $\alpha_{V}$ relevant to transverse isotropy). Total seam horizontal stress $\sigma_{h}$ and vertical stress $\sigma_{V}$ are affected by the strain tensor $\underline{\underline{\varepsilon}}$, the pore pressure in the cleats $p_{c}$, and the adsorption-strain coupling through the adsorption stress $s^{a}$ weighed by the Biot coefficients. The following applies when horizontal stresses are the same in both directions.

$$
\left\{\begin{aligned}
\sigma_{h} & =\left(C_{11}+C_{12}\right) \varepsilon_{h}+C_{13} \varepsilon_{V}-\alpha_{h} p_{c}-\left(1-\alpha_{h}\right) s^{a}\left(p_{m}\right) \\
\sigma_{V} & =2 C_{13} \varepsilon_{h}+C_{33} \varepsilon_{V}-\alpha_{V} p_{c}-\left(1-\alpha_{V}\right) s^{a}\left(p_{m}\right)
\end{aligned}\right.
$$

The adsorption stress $s^{a}\left(p_{m}\right)$ developed by the coal matrix depends on the amount of adsorbed fluid in the coal matrix $n_{m}\left(p_{m}, \epsilon_{m}\right)$ and swelling properties of the coal matrix as follows, 


$$
s^{a}\left(p_{m}\right)=\left.\int_{0}^{p_{m}} \frac{\partial n_{m}}{\partial \epsilon_{m}}\right|_{p_{m}} \bar{V}_{b}\left(p_{m}\right) d p_{m}
$$

where the thermodynamical pressure $p_{m}$ is the pressure of the bulk fluid at the same chemical potential of the adsorbed phase phase in the coal matrix. $V_{b}\left(p_{m}\right)$ is the molar volume of the fluid phase in bulk conditions. The amount of adsorption in the coal matrix $n_{m}$ depends on fluid thermodynamical pressure $p_{m}$ as well as on the coal matrix strain $\epsilon_{m}$ (Brochard et al., 2012). A first order approximation permits expressing this amount as

$$
n_{m}\left(p_{m}, \epsilon_{m}\right)=n_{m 0}\left(p_{m}\right)\left[1+c\left(p_{m}\right) \epsilon_{m}\right]
$$

where $n_{m 0}\left(p_{m}\right)$ is the adsorption isotherm at zero volumetric strain, here approximated as a Langmuir type isotherm on pressure $n_{m 0}\left(p_{m}\right)=n_{0}^{\max }\left[p_{m} /\left(p_{m}+\right.\right.$ $\left.\left.p_{L 0}\right)\right]$, and $c\left(p_{m}\right)$ is the adsorption-strain coupling coefficient. The coal seam poroelastic coefficients relate to initial cleat macroporosity $\phi_{c 0}$ and the bulk modulus of the coal matrix $K_{m}$ through micromechanical equations shown elsewhere (Espinoza et al., 2014).

The pressure $p_{m}$ at the coal matrix can be different from the fracture cleat pressure $p_{c}$ if the coal matrix and the seam are not in thermodynamical equilibrium. Reservoir depletion implies a change of fluid pressure in fractures $\Delta p_{c}$ (fracture drainage) and a change in the coal matrix thermodynamical equilibrium pressure $\Delta p_{m}$ (desorption). Under zero-lateral strain condition, the changes of lateral stresses and vertical strain are the following (Equation 1): 
377

$$
\left\{\begin{aligned}
\Delta \sigma_{h} & =\left(\frac{C_{13}}{C_{33}} \alpha_{V}-\alpha_{h}\right) \Delta p_{c}+\left[\frac{C_{13}}{C_{33}}\left(1-\alpha_{V}\right)-\left(1-\alpha_{h}\right)\right] \frac{d s^{a}\left(p_{m}\right)}{d p_{m}} \Delta p_{m} \\
\Delta \varepsilon_{V} & =\frac{1}{C_{33}} \alpha_{V} \Delta p_{c}+\frac{1}{C_{33}}\left(1-\alpha_{V}\right) \frac{d s^{a}\left(p_{m}\right)}{d p_{m}} \Delta p_{m}
\end{aligned}\right.
$$

where

$$
\left\{\begin{array}{l}
\frac{C_{13}}{C_{33}}=\frac{E \nu_{3}}{E_{3}(1-\nu)} \\
\frac{1}{C_{33}}=\frac{1-\nu-2\left(E / E_{3}\right) \nu_{3}^{2}}{E_{3}(1-\nu)}
\end{array}\right.
$$

in terms of Young's modulus parallel to the bedding plane $E$, Poisson's ratio in the bedding plane $\nu$, Young's modulus perpendicular to the bedding plane $E_{3}$ and Poisson's ratio in planes perpendicular to the bedding plane $\nu_{3}$.

Notice that both $\sigma_{h}$ and $\varepsilon_{V}$ depend on variations of the fluid pressure in the cleats $\Delta p_{c}$ (conventional poroelastic path) and variations of fluid pressure in the coal matrix $\Delta p_{m}$ (desorption path).

\subsection{Model parameters}

Previous work from the authors measured the adsorptive-mechanical properties of the coal cores tested in this study (Espinoza et al., 2014). Table 3 summarizes the best fitting parameters of the fully coupled double-porosity transverse isotropic poroelastic model introduced above.

\subsection{Numerical simulation of $\mathrm{CO}_{2}$ desorption experiment at zero-lateral strain condition}

Let us simulate experiment V2b shown in Figures 6 and 7 . The experiment follows the loading path summarized in Table 4.

Event (4) depletion-desorption is decomposed into the variation of pressure in the cleats $\Delta p_{c}$ and then coal matrix desorption $\Delta p_{m}$. Figure 11 
Table 3: Parameters of poroelastic model for coal cores with dual porosity, i.e., cleat and coal matrix porosity.

\begin{tabular}{c|c}
\hline \hline Core scale & Matrix scale \\
\hline$E=2736 \mathrm{MPa}$ & $K_{m}=5000 \mathrm{MPa}$ \\
\hline$E_{3}=2551 \mathrm{MPa}$ & $n_{0}^{\max }=2.4 \mathrm{~mol} / \mathrm{L}\left(\mathrm{CO}_{2}\right)$ \\
\hline$\nu=0.267$ & $p_{L 0}=1.6 \mathrm{MPa}\left(\mathrm{CO}_{2}\right)$ \\
\hline$\nu_{3}=0.267$ & $c=11\left(\mathrm{CO}_{2}\right)$ \\
\hline$\phi_{c 0}=0.08$ & \\
\hline \hline
\end{tabular}

Table 4: Desorption experimental pressure-stress path and boundary conditions for experiments V2b.

\begin{tabular}{l|c|c|c}
\hline \hline Event & Axial stress $\sigma_{r}$ & Radial stress $\sigma_{a}$ & Fluid pressure $p_{c}$ \\
\hline $\begin{array}{l}\text { 1) Dry loading to isotropic } \\
\text { state of stress }\end{array}$ & $\begin{array}{c}0 \text { to }-12 \mathrm{MPa} \\
\text { (Prescribed) }\end{array}$ & $\begin{array}{c}0 \text { to }-12 \mathrm{MPa} \\
\text { (Prescribed) }\end{array}$ & None \\
\hline 2) $\mathrm{CO}_{2}$ injection and adsorption & $-12 \mathrm{MPa}$ & $-12 \mathrm{MPa}$ & 0 to $10 \mathrm{MPa}$ \\
at constant confining stress & (Prescribed) & (Prescribed) & (Prescribed) \\
\hline 3) Increase of stress anisotropy & -12 to $-30 \mathrm{MPa}$ & -12 to $-15 \mathrm{MPa}$ & $10 \mathrm{MPa}$ \\
to the initial state of stress & (Prescribed) & (Prescribed) & (Prescribed) \\
\hline 4) Depletion-desorption & $-30 \mathrm{MPa}$ & variable & 10 to $1 \mathrm{MPa}$ \\
& (Prescribed) & to maintain $\Delta \varepsilon_{r}=0$ & (Prescribed) \\
\hline \hline
\end{tabular}



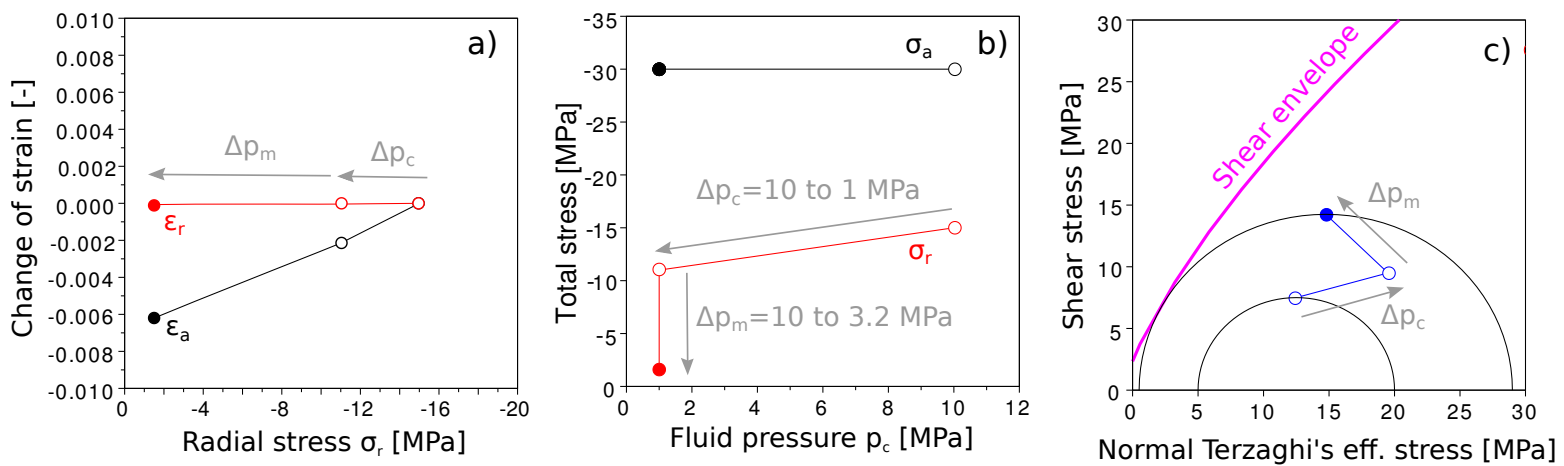

Figure 11: Numerical simulation of coal core depletion-desorption of $\mathrm{CO}_{2}$ under zerolateral strain condition. (a) Change of strains. (b) Total stresses. (c) Terzaghi's effective stress Mohr circle.

shows the numerical simulation results starting from event (4). Deformation is taken as a reference equal to zero at the beginning of event (4).

The pressure drawdown promotes gas drainage from fractures and gas desorption from the coal matrix. The poroelastic response of fractures is proportional to $\Delta p_{c}=-9 \mathrm{MPa}$ and promotes a shortening of the specimen $\Delta \varepsilon_{a}=-0.002$, reduction of total radial stress $\Delta \sigma_{r}=-4 \mathrm{MPa}$, and movement of the apex of the effective stress Mohr circle in up-right direction with a decrease of the maximum ratio of shear to normal effective stress. The effect of desorption is proportional to $\Delta p_{m}$. As $p_{m}$ decreases, the specimen shortens further in vertical direction, radial stress becomes less compressive, and the apex of the effective stress Mohr circle moves in up-left direction. In Figure 11, $p_{m}$ varies from $10 \mathrm{MPa}$ to $3.2 \mathrm{MPa}$. The thermodynamic pressure of the coal matrix cannot go lower because the core fails in shear at $p_{m}=3.2 \mathrm{MPa}$. Hence, the modeling results suggest that experiment V2b shown in Section 3 would have failed for any drawdown pressure lower than $\sim 3.2 \mathrm{MPa}$ using 
$\mathrm{CO}_{2}$.

We simulate the loading path followed upon depressurization for all desorption experiments in zero-lateral strain condition. The simulation is based on the initial stress and pressure conditions shown in Table 2 assuming that cleat depressurization occurs first $\Delta p_{c}$ and desorption follows $\Delta p_{m}$. The final simulation pressure-stress point is chosen to be the point at which effective stresses reach the Hoek-Brown criterion (Experiment V2a,V2b, and V3b) or the point at which Terzaghi's radial effective stress becomes zero $\sigma_{r}+p_{c}=0$ (Experiment V3a). The latter condition reflects the fact that the radial confining pressure (radial stress) cannot be set lower than the fluid pressure experimentally because the fluid would escape into the confining fluid.

Table 5 summarizes the values of cleat pressure, radial stress and thermodynamic pressure in the coal matrix at the final pressure-stress simulation point. The simulation predicts shear failure for experiment V2a as opposed to what is observed experimentally, although the difference between $p_{m f}$ and $p_{c f}$ is small suggesting that the model was not too far from predicting the right value. Experiment V3a starts with a low axial stress, thus it is not expected to fail even if lateral stress goes to zero, however, numerical simulation help calculate the reduction in lateral stress to near zero effective lateral stress as observed experimentally. The model does predict the shear failure of experiments V2b and V3b. Furthermore, the numerical simulation suggests that these experiments were ended (because of shear failure) significantly before achieving thermodynamical equilibrium $p_{m f}>p_{c f}$. 
Table 5: List of simulated $\mathrm{CO}_{2}$ zero-lateral strain desorption experiments: final pressurestress conditions. Initial conditions are described in Table 2.

\begin{tabular}{c|cccc}
\hline \hline & $\begin{array}{c}\text { Final pressure } \\
\text { in cleats }\end{array}$ & $\begin{array}{c}\text { Predicted radial } \\
\text { radial stress at } \\
\text { the end of the test } \\
\text { Simulated }\end{array}$ & $\begin{array}{c}\text { Predicted coal matrix } \\
\text { fluid pressure at } \\
\text { the end of the test }\end{array}$ & $\begin{array}{c}\text { Hoek-Brown } \\
\text { criterion } \\
\text { achieved? }\end{array}$ \\
\hline V2a & $\begin{array}{c}\sigma_{c f} \\
{[\mathrm{MPa}]}\end{array}$ & $\begin{array}{c}p_{m f} \\
{[\mathrm{MPa}]}\end{array}$ & $\begin{array}{c}\text { Shear failure } \\
{[\mathrm{Y} / \mathrm{N}]}\end{array}$ \\
\hline V3a & 0.5 & -1.0 & 1.6 & $\mathrm{Y}$ \\
\hline V2b & 1.0 & -0.5 & 3.5 & $\mathrm{~N}$ \\
\hline V3b & 1.0 & -1.5 & 3.2 & $\mathrm{Y}$ \\
\hline \hline
\end{tabular}

\subsection{Numerical simulation of analogous desorption experiment with $\mathrm{CH}_{4}$}

Let us now simulate what the response of an analogous experiment using $\mathrm{CH}_{4}$ would be. We roughly assume that coal would swell about a third as much with $\mathrm{CH}_{4}$ compared to $\mathrm{CO}_{2}$ at the same fluid pressure (see Section 4.1). Hence, we approximate the parameters of the coal matrix with $n_{0}^{\max }=$ $1.2 \mathrm{~mol} / \mathrm{L}$ and $c=6$. The simulation follows the path stipulated in Table 4 and the results are shown in Figure 12. Clearly there is less pronounced reduction of radial stress due to desorption in this case compared to the case with $\mathrm{CO}_{2}$ desorption. As expected, the fracture poroelastic response is exactly the same in both cases.

The model predicts that shear failure does not occur with $\mathrm{CH}_{4}$ given the initial pressure-stress conditions, even though $p_{m}$ reaches the drawdown pressure $p_{m}=p_{c}=1 \mathrm{MPa}$. Field scale seams have negligible unconfined compression strength, hence, the friction strength of fractures could be chal- 

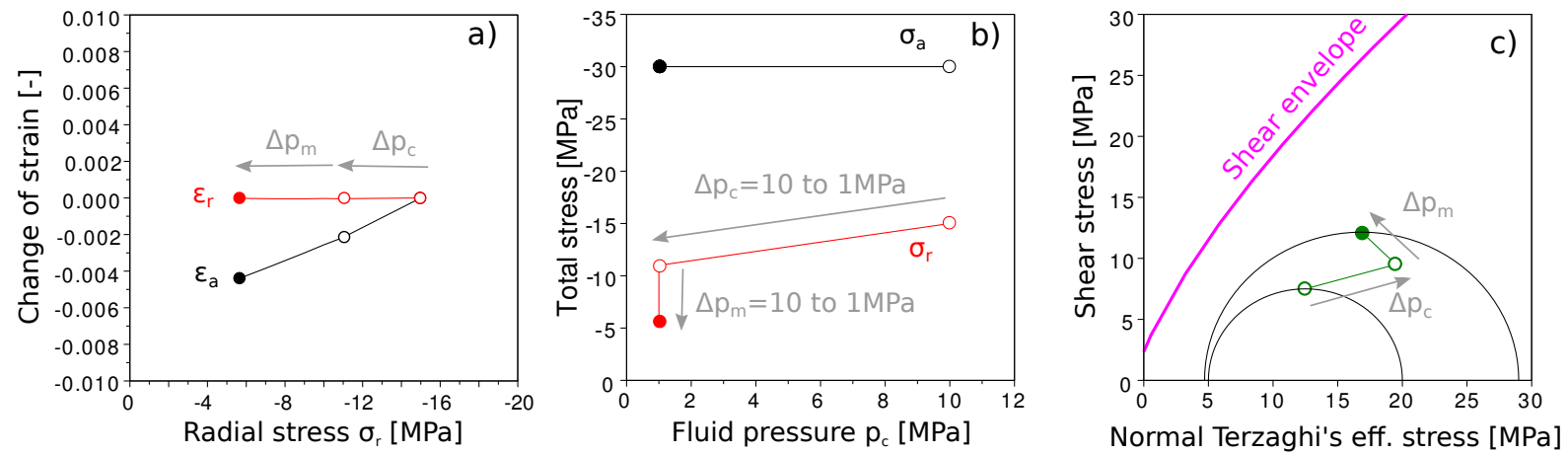

Figure 12: Numerical simulation of coal core depletion-desorption of $\mathrm{CH}_{4}$ under zerolateral strain condition. (a) Change of strains. (b) Total stresses. (c) Terzaghi's effective stress Mohr circle.

447

lenged by change of stresses induced by desorption. Even with $\mathrm{CH}_{4}$, the increase of stress anisotropy and movement of the apex of the Mohr circle in up-left direction may induce state of stress with ratio of shear stress to effective normal stress high enough to promote shear failure of existent fractures and fines production.

\section{Conclusions}

Deep coal beds have unique transport and mechanical properties, and hence, they require particular completion and production strategies. Desorptioninduced coal shrinkage is advantageous because it increases permeability upon depletion. Yet, extensive coal mechanical failure and fracture plugging with fines has sometimes been observed after steep increases of permeability. It is known that near-wellbore stress concentration and fracture poroelastic response help increase stress anisotropy in the reservoir rock upon depletion and may favor shear failure. Far from the wellbore, the coal seam is 
expected to follow compression under zero-lateral strain and constant total vertical stress. At this condition, we show through triaxial experiments that reduction of lateral stress induced by the shrinkage of the coal matrix during gas desorption can significantly favor coal shear failure far from the wellbore. Performed tests show a clear increase of stress anisotropy induced by desorption, in some cases leading to shear failure.

The stress path under zero-lateral strain condition depends on variations of pore pressure in the coal cleats and on variations of stresses caused by gas desorption from the coal matrix. In general, two parts of the stress path can be recognized: (1) conventional stress path characterized by the poroelastic coefficient $\alpha(1-2 \nu) /(1-\nu)$ and induced by variation of the fluid pressure in the cleats $p_{c}$, and (2) desorption-induced decrease in lateral stress defined by the adsorptive-mechanical properties of the coal matrix and promoted by a variation of adsorption stress in the coal matrix. The steep slope of the desorption-induced path can reach the failure envelope and promote shearing sooner than would happen for a conventional non-adsorptive reservoir rock. Coal failure can be predicted by knowing the original state of stresses, coal shear failure envelope, and the mechanical-adsorptive properties of the coal. We developed a model that links all these variables and showed its application to match laboratory experiments. Coupled numerical simulation considering more realistic boundary conditions and completion details is needed to validate our findings to specific field observations. To the best of our knowledge, this is the first model that offers a consistent analysis on the depletion of coal seams and ensuing failure, incorporating explicitly a stress path solely due to desorption. 
493

\section{Acknowledgements}

This work was supported by Total S.A. The technical support provided by E. De Laure and his team at Laboratoire Navier-CERMES is greatly appreciated. We are thankful to N. Lenoir for providing the X-ray images and to S. Hol and an anonymous reviewer for insightful comments that helped improving this manuscript.

\section{Symbols}

$\alpha \quad$ Biot coefficient [-]

$\varepsilon \quad$ Strain $[-]$

$\phi_{c} \quad$ Macroporosity [-]

$\mu \quad$ Friction coefficient [-]

$\nu \quad$ Poisson's ratio [-]

$\sigma \quad$ Total stress $[\mathrm{Pa}]$

$\sigma^{\prime} \quad$ Effective stress $[\mathrm{Pa}]$

$\tau \quad$ Shear stress $[\mathrm{Pa}]$

A Poroelastic depletion slope [-]

$C_{i j} \quad$ Stiffness tensor coefficient [-]

E Young's modulus [E]

$p_{m} \quad$ Thermodynamical pressure of the coal matrix $[\mathrm{Pa}]$

$p_{c} \quad$ Pressure in cleats $[\mathrm{Pa}]$

\section{References}

Boutéca, M., Guéguen, Y., 1999. Mechanical properties of rocks: pore pressure and scale effects. Oil \& Gas Science and Technology Rev. IFP 54, 
703-714.

Brochard, L., Vandamme, M., Pellenq, R.J.M., 2012. Poromechanics of microporous media. Journal of the Mechanics and Physics of Solids 60, 606622 .

Cartwright, J.A., Lonergan, L., 1996. Volumetric contraction during the compaction of mudrocks: a mechanism for the development of regional-scale polygonal fault systems. Basin Research 8, 183-193. doi:10.1046/j.13652117.1996.01536.x.

Ceglarska-Stefanska, G., Czaplinski, A., 1993. Correlation between sorption and dilatometric processes in hard coals. Fuel 72, 413-417.

Chikatamarla, L., Bustin, R., Cui, X., 2009. CO2 sequestration into coalbeds: insights from laboratory experiments and numerical modeling, in: Grobe, M., Pashin, J.C., Dodge, R.L. (Eds.), Carbon dioxide sequestration in geological media - State of the science: AAPG Studies in Geology 59, pp. $457-474$.

Czaplinski, A., Holda, S., 1982. Changes in mechanical properties of coal due to sorption of carbon dioxide vapour. Fuel 61, 1281-1282.

Dikken, B., Niko, H., 1987. Waterflood-induced fractures: a simulation study of their propagation and effects on waterflood sweep efficiency, in: Proceedings of Offshore Europe, Society of Petroleum Engineers. doi:10.2118/16551-MS.

EIA, 2013. International Energy Outlook 2013 - Report number: DOE/EIA0484(2013). Technical Report. 
Espinoza, D.N., Vandamme, M., Dangla, P., Pereira, J.M., Vidal-Gilbert, S., 2013. A transverse isotropic model for microporous solids - Application to coal matrix adsorption and swelling. Journal of Geophysical Research Solid Earth 118, 6113-6123.

Espinoza, D.N., Vandamme, M., Pereira, J.M., Dangla, P., Vidal-Gilbert, S., 2014. Measurement and modeling of adsorptive-poromechanical properties of bituminous coal cores exposed to CO2: adsorption, swelling strains, swelling stresses and impact on fracture permeability. International Journal of Coal Geology doi:10.1016/j.coal.2014.09.010.

Goulty, N.R., 2003. Reservoir stress path during depletion of Norwegian chalk oilfields. Petroleum Geoscience 9, 233-241. doi:10.1144/1354-079302-545.

Hagin, P., Zoback, M.D., 2010. Laboratory studies of the compressibility and permeability of low-rank coal samples from the Powder River Basin, Wyoming, USA, in: ARMA 10-170.

Hol, S., Gensterblum, Y., Massarotto, P., 2014. Sorption and changes in bulk modulus of coal experimental evidence and governing mechanisms for CBM and ECBM applications. International Journal of Coal Geology 128-129, 119-133. doi:10.1016/j.coal.2014.04.010.

Hol, S., Spiers, C.J., Peach, C.J., 2012. Microfracturing of coal due to interaction with CO2 under unconfined conditions. Fuel 97, 569-584.

IEA, 2013. Key world energy statistics 2013. Technical Report.

Laubach, S.E., Marrett, R.A., Olson, J.E., Scott, A.R., 1998. Characteristics 
542

and origins of coal cleat: A review. International Journal of Coal Geology $35,175-207$.

Levine, J.R., 1996. Model study of the influence of matrix shrinkage on absolute permeability of coal bed reservoirs. Geological Society, London, Special Publications 109, 197-212. doi:10.1144/gsl.sp.1996.109.01.14.

Majer, E.L., Baria, R., Stark, M., Oates, S., Bommer, J., Smith, B., Asanuma, H., 2007. Induced seismicity associated with Enhanced Geothermal Systems. Geothermics 36, 185-222. doi:10.1016/j.geothermics.2007.03.003.

Masoudian, M., Airey, D., El-Zein, A., 2013. A chemo-poro-mechanical model for sequestration of carbon dioxide in coalbeds. Geotechnique 63, $235-243$.

Masoudian, M.S., Airey, D.W., El-Zein, A., 2014. Experimental investigations on the effect of $\mathrm{CO} 2$ on mechanics of coal. International Journal of Coal Geology 128-129, 12-23. doi:10.1016/j.coal.2014.04.001.

Mazumder, S., Karnik, A., Wolf, K.H., 2006. Swelling of coal in response to CO2 sequestration for ECBM and its effect on fracture permeability. SPE Journal 11, 390-398.

Mitra, A., Harpalani, S., Liu, S., 2012. Laboratory measurement and modeling of coal permeability with continued methane production: Part 1 Laboratory results. Fuel 94, 110-116. doi:10.1016/j.fuel.2011.10.052.

Moore, R.L., Loftin, D., Palmer, I., 2011. History matching and permeability increases of mature coalbed methane wells in San Juan Basin, in: SPE Asia 
Pacific Oil and Gas Conference and Exhibition, 20-22 September, Jakarta, Indonesia.

Nikoosokhan, S., Vandamme, M., Dangla, P., 2012. A poromechanical model for coal seams injected with carbon dioxide: from an isotherm of adsorption to a swelling of the reservoir. Oil \& Gas Science and Technology Rev. IFP, Energies nouvelles 67, 777-786.

Nikoosokhan, S., Vandamme, M., Dangla, P., 2014. A poromechanical model for coal seams saturated with binary mixtures of $\mathrm{CH} 4$ and CO2. Journal of the Mechanics and Physics of Solids 71, 97-111. doi:10.1016/j.jmps.2014.07.002.

Okotie, V.U., Moore, R.L., 2010. Well Production challenges and solutions in a mature, very low-pressure coalbed methane reservoir, in: Canadian Unconventional Resources and International Petroleum Conference, 19-21 October, Calgary, Alberta, Canada.

Palmer, I., 2008. Failure during CO2 injection in the field, in: Coal-seq VI, April 10-11, Houston, Texas.

Palmer, I., Mansoori, J., 1998. How permeability depends on stress and pore pressure in coalbeds: A new model. Evaluation , 539-544.

Pan, Z., Connell, L.D., 2011. Modelling of anisotropic coal swelling and its impact on permeability behaviour for primary and enhanced coalbed methane recovery. International Journal of Coal Geology 85, 257-267. doi:10.1016/j.coal.2010.12.003. 
Pan, Z., Connell, L.D., 2012. Modelling permeability for coal reservoirs: A review of analytical models and testing data. International Journal of Coal Geology 92, 1-44. doi:10.1016/j.coal.2011.12.009.

Pan, Z.J., Connell, L.D., 2007. A theoretical model for gas adsorptioninduced coal swelling. International Journal of Coal Geology 69, 243-252.

Pini, R., 2009. Enhanced coal bed methane recovery finalized to carbon dioxide storage. Ph.D. thesis. ETH Zurich.

Reucroft, P.J., Sethuraman, A.R., 1987. Effect of pressure on carbon dioxide induced coal swelling. Energy Fuels 1, 72-75.

Segall, P., Fitzgerald, S.D., 1998. A note on induced stress changes in hydrocarbon and geothermal reservoirs. Tectonophysics 289, 117-128.

Shin, H., Santamarina, J.C., Cartwright, J.A., 2010. Displacement field in contraction-driven faults. Journal of Geophysical Research 115.

Teufel, L.W., Rhett, D.W., Farrell, H.E., 1991. Effect of reservoir depletion and pore pressure drawdown on in situ stress and deformation in the Ekofisk field, North Sea, in: Rock Mechanics as a Multidisciplinary Science, Roegiers (ed), pp. 63-72.

Zoback, M.D., 2013. Reservoir geomechanics. Cambridge University Press, New York. 